\title{
3. THE PARTICULIARITIES OF CHOIR CONDUCTOR TRAINING OF THE CHINESE STUDENT AT MUSICAL AND PEDAGOGICAL INSTITUTIONS IN UKRAINE
}

\section{Inna Kovalenko ${ }^{4}$}

\begin{abstract}
This article deals with the problem of choir conductor training of the Chinese students. It discloses the peculiarities and the difficulties in their training at higher musical and pedagogical institutions in Ukraine.
\end{abstract}

Key words: musical and pedagogical education, choir conductor training, foreign students

\section{Introduction}

The beginning of the $21^{\text {st }}$ century is marked with a new social and historical era of humanity, in which the exchange of cultural heritage becomes the pattern of democratic relations on international level. Due to the modern policy of openness, the countries that are geographically separated by a great distance are able to learn the national culture of the interested country and integrate into the united cultural and educational space, exchange the valuable knowledge in various branches of science, art and technology. The significance of the whole process lies in the necessity of needed information exchange which serves as an additional social and economic resource and factor of spiritual capacity-building of society, strategic framework of individual development and the near future for each state and community. Revival and renewal of cultural and educational capacity of each nation is the base for cultural and educational potential of the nation and all mankind, as well the dynamic movement to the civilization progress, world mankind's common cultural and educational interests and values.

\section{Discussions}

Important mission falls on the destiny of future arts teachers, who should reestablish the national cultural traditions of their people, enrich with new creative achievements, methods of preservation and distribution as well a new wave of interest of new generation towards various genres as the successors of glorious historical traditions. The interest of Chinese youth to vocal and choir music, in particular to conductor art, has improved lately, so the acknowledgment with the Ukrainian expertise of vocal and choir as well conductor preparation of future teachers becomes essential. To resolve above mentioned problems of state level, the Chinese youth entered National Pedagogical Dragomanov University (Ukraine) to gain professional training of future teachers of musical arts, where vocal and choir training is the leading discipline and also master's degree on chorus's leader and teacher of conducting are available.

The relevance of our research is connected with the case study of interest formation of this ethic group towards the Ukrainian national vocal and choir art; its creative rethinking, adaptation and adjustment to Chinese pedagogical

\footnotetext{
${ }^{4}$ Professor PhD., National Pedagogical Dragomanov University from Kyev, Ukraine, email: inna7ori@gmail.com 
technologies borrowed from Ukrainian pedagogical heritage is an area of particular interest. As the result of state policy of openness conducted by People's Republic of China, the Chinese youth could gain the higher education in other countries of the world and get acknowledged with the new technologies of the world cultural dynamic as well borrow the best national tradition of other peoples transforming them to the contemporary cultural and educational needs and progress of China.

It is necessary to admit that there have appeared lately some quite fascinating studies on usage of musical and pedagogical experience of higher institution and preparation of future teachers of musical arts to work in the secondary schools in China (Lin Hai [4], Ma Hu [5], etc.) The Chinese modern researchers in the pedagogy field pay much attention to the necessity on reforming higher school in China, familiarization with new world educational technologies of foreign countries that are focused on development of human spiritual values through traditions of other peoples.

The higher musical education has defined humanism, democracy, priority of fundamental spiritual values of humanity by the leading educational principles [1]. National vocal and choir art is the only means to influence on children and youth's formation of high spiritual characters of a personality, understanding of originality and uniqueness of Ukrainian musical art, bringing up their musical interests and preferences, promoting respect to national holy sites as well cultural and historical traditions.

The analysis of source materials on the problems of conductor training of student showed that there should be outlined the content and methods, thus enabling foreign students to be equipped with the methodological guidelines for motivation and interest towards the national vocal and choir art and the corresponding training to choir conductor activity with the further transformation of acquired knowledge into the educational system of China.

To achieve the goal, we outlined the methodological principles based on which the interest of vocal and choir art in general and choir conductor activity in particular is grounded. There should be broadened the motivation spheres: interest to national choir traditions as well vocal and choir activity, commitment and need in professional self-improvement; enhancing educational and methodological, vocal and choir, performance and creative experience of Chinese students; stimulating creative potential and skills to conduct choir; developing ability of artistic usage of professional achievements.

\section{Results}

While training foreign students, the scholars of higher institution should maintain the certain conditions and set the task as follows:

- stimulate interest to conducting activity;

- gain theoretical and practical experience of communication and interaction in the artistic group;

- enlarge theoretical choir knowledge base and acquire skills and capabilities that ensures the quality of conducting preparation and practice of vocal and choir performance; 
- learn the system od methods and methodologies of independent analysis of choir works, methodology of work with choir group (both children and adult groups), interpretation of choir works, artistic and emotional conducting of choir works not only of national character but world heritage as well;

- develop musical and manual memory and artistic taste, enhance the basis of conducting technique and abilities to use the in different masterly performance;

- accumulate vocal and choir repertoire using the works of Chinese and world culture;

- shape professional and personal qualities of future conductors of choir group;

The quality of choir conductor training of foreign students depends upon the level of motivation and cognitive interest, which is considered as the composition of cognitive, emotional, psychological and other personal characteristics, being the leading and powerful agent of cognitive, behavior and other actions of an individual. Motivation and interest to choir conductor activity is based on ethnic and pedagogical methodological principles as well the complex of mutually referential fundamentals of various spheres (philosophy, education, psychology and pedagogy, the importance of vocal and choir art in the development of an individual).

Choir conductor training is the synthesis of various knowledge, skills and capabilities that secure multi-level professional position of future teacher of musical arts. Student training in this trend of musical activity is the integral part of complex training of the specialist, which is learnt due to the purposefully arranged system of academic musical and pedagogical as well national training at higher institutions. The efficiency of choir conductor training of foreign students depends on integrity and consistency of training.

Choir conductor training of Chinese students has quite a lot of difficulties. Let us mention some of them. Firstly, most of the Chinese students enter the higher musical and pedagogical institution without the sufficient musical education or having extremely low elementary musical education. Secondly, most of the Chinese students $(90 \%)$ don't have the experience in singing at choir group. Thirdly, most of the Chinese students speak poorly Russian or Ukrainian, which leads to the barrier in the communication, training as well understanding between a student and a teacher. Upon such circumstances the teacher of higher institution has great responsibility in organizational and educational work at the primary level to provide the strong support and pedagogical follow-up, account by teacher of all difficulties of adaptation period for foreign students.

Training of foreign students for future professional activity is carried out based on such disciplines: choir class and conducting. The content of mentioned disciplines focuses on student training for vocal and choir work at performance groups and institutions. The individual for of education (which is the base for learning the discipline "conducting" as performance art) assists in effective solving of difficult tasks of this course. The professional activity of modern specialist as conductor-choirmaster allows to define the main tasks of the course "Conducting" with the help of such factors: learning various conducting technique; formation of skills of self-guided work under vocal and choir works; establishing performance interpretation in the process of unsupervised processing 
of choir work; conducting the best examples of choir literature; learning the methodology of choir rehearsal; developing musical and creative capabilities and skills, musical and innovative thinking of students.

The importance of discipline "Conducting" within the disciplines of conductor and choir cycle lies in the integral coverage of complex aspects of conductor and choir training during all training period. It has great potential possibilities for the versatile development of creative activity of choir conductor. The subject "Conducting" which is considered as the important level of the structure of conductor and choir disciplines, by its context, stepwise implementation in the training process, functions etc., features own system, i.e. it is complex, multi-level, multifunctional subsystem [7].

The primary level (the definition of technique of conducting) is compiled from subordinated elements which are interconnected and places upon the principle of distance from the main elements to the secondary ones (i.e. the structure of conductor apparatus, problem of differentiation of hand functions while conducting, the elements of conductor gesture, learning conductor schemes, conductor implementation of auftact, dynamics and its reproduction in the conductor gesture, depicting conductor's gesture fermata).

The general connection between technical and artistic sides of performance activity is so natural that in some cases the skillful realization of work seems as a complete whole entity. The outstanding artists pointed out to this peculiarity of performance process. The difficulty of technical part of conductor art causes to separate the process of manual technique acquisition into the special course chapter "Conducting". Theoretical comprehension of the essence of conductor activity shapes the contemporary understanding of conductor technique that we describe in wide and narrower definition. In general understanding the conductor technique is defined as the complex of activities designated to achieve the phonation that would be adequate to conductor's musical understanding. Both the dialectical integrity of technical and artistic levels of performance and understanding the process of sound implementation of performance intention foster the perception of conductor technique definition. The function of conductor's internal activities, imaginary music-making and its correlation with real sounding of choir or orchestra as well the needed correction of sounding provide the possibility for a conductor not just to pass the external form of work (technical level of performance) but also comprehend the deep essence of musical images, create an individual performance interpretation (artistic level).

The narrow definition of understanding of conductor technique includes the implementation of performance concept with the means of conductor's plastic complex in particular conductor's gesture and mimic. The specific character of conductor's gesture lies in the immediate corresponding reaction of performer, thus making it the most effective influential mean for the group (both in the concert and rehearsal processes). The bulk of conductor's gestures correlates with such principles as freedom, clearness, frugality, practibility, exactness, rhythmicality. At the time of conducting the meaningful gesturers, the flow of spiritual impulses, the type of information which the conductor passes to the performance group are vital. 
The individual work of students under the choir works has great value: performance interpretation of work, score analysis, vocal and intonation as well conducting and technical implementation. The definition of interpretation (as sound actualization of score) presupposes the individual approach to music performance, its active perception, performer's own creative conception of implementation of author's message. The learning of choir work covers three mutually connected steps: the individual studying of score by a student, group rehearsal, and concert performance. The first mentioned step which is connected with the necessity of internal possession of choir work, outlining the flexible rehearsal schedule, sets up the base for conductor's work.

The learning of choir work in the individual class of choir conducting is long-lasting and structure complicated process. The specific difficulty of such work with foreign students, unlike the musicians of other disciplines, is the absence of influence object at the time of pre-rehearsal period. The peculiarity of future conductor's activity presupposes such level of future score sounding before the rehearsal. The development of ability for the imaginary modeling of artistic and presentative sounding of choir work is considered as one of the ost difficult problem in conductor pedagogy.

\section{Conclusions}

The analysis of choir music is obligatory for professional training for the future conductor-choir master. Theoretical and analytical approach to music allows shaping the meaningful, visibly reasoned interpretation; approaching the composer's intention and providing the possibility for the performer to display creative individuality. The important structural elements of performance analysis of choir work are: general historical and stylistic, literature and context, musical and theoretical, vocal and choir as well own performance analyses.

We introduce the following major types of work at choir and conducting classes for foreign students: creation the psychological conditions that model the course of rehearsal at the conducting classes; conducting and technical definitions on the structure of rehearsal process; carrying out the certain fragments of rehearsal. Thus we attempt to create the variability of organizational types of training, which has the great significance for choir conductor training of the Chinese students.

Finally, choir conductor training of foreign students requires the development of context and methodology which ensures the Chinese students of higher art institutions of Ukraine with the methodological means of stimulation and interest development towards national vocal and choir art as well the corresponding preparation of this trend to choir conductor activity and the leadership of choir or vocal groups for the further knowledge transformation into the educational system of People's Republic of China.

\section{References}

1. Andrushchenko V.P. The arts education in the formation of teacher of $21^{\text {st }}$ century / Research journal of National Pedagogical Dragomanov University. 
Series 14 . Theory and methodology of arts education: Collection of studies. - K.: NPU, 2004. - Issue.1 (6). - P. 4-6. (in Russian)

2. Vasil'ev V.A. The sketches on conductor and choir training: succession of traditions and development trends. - M.: Music, 1991. - 117 p. (in Russian)

3. Karpenko E.V. Conductor and choir training of music teacher: Research and methodological manual - Sumy: VVP "Maria” 2001, - 110 p. (in Ukrainian)

4. Lin Hai. Methodological means of conductor and choral preparation of student for the work at schools in China and Ukraine: thesis of pedagogical sciences: 13.00.02 / Lin Hai. - K., 2007. - 19 p. (in Ukrainian)

5. Ma Xu. The training experience of foreign students, future leaders of choir groups at higher academic institutions in Ukraine / Ma Xu // Pedagogical sciences: theory, history, innovation technologies: research journal / MES Ukraine, Sumy State Pedagogical Makarenko University; [editors: A. A. Sbrueva, O. E. Antonova, J. Bishop etc.]. - Sumy : SumySPMU. - 2015. - № 1 (45). - P. 321 331. (in Ukrainian)

6. Orlov V.F. Career winning of the teacher of arts diciplines: (Monograph / Editor I.A.Zyazina - K.: Research idea, 2003. - 276 p. - Ref.: p.252-263. (in Ukrainian)

7. Smirnova T.A. Higher choir and conductor education in Ukraine: past and present: Monograph. - Kharkov: Konstanta, 2002. - 256 p. - Ref.: p.236-256. (in Ukrainian) 